\title{
Neutron Characterization of Additively Manufactured Components: Workshop Report
}

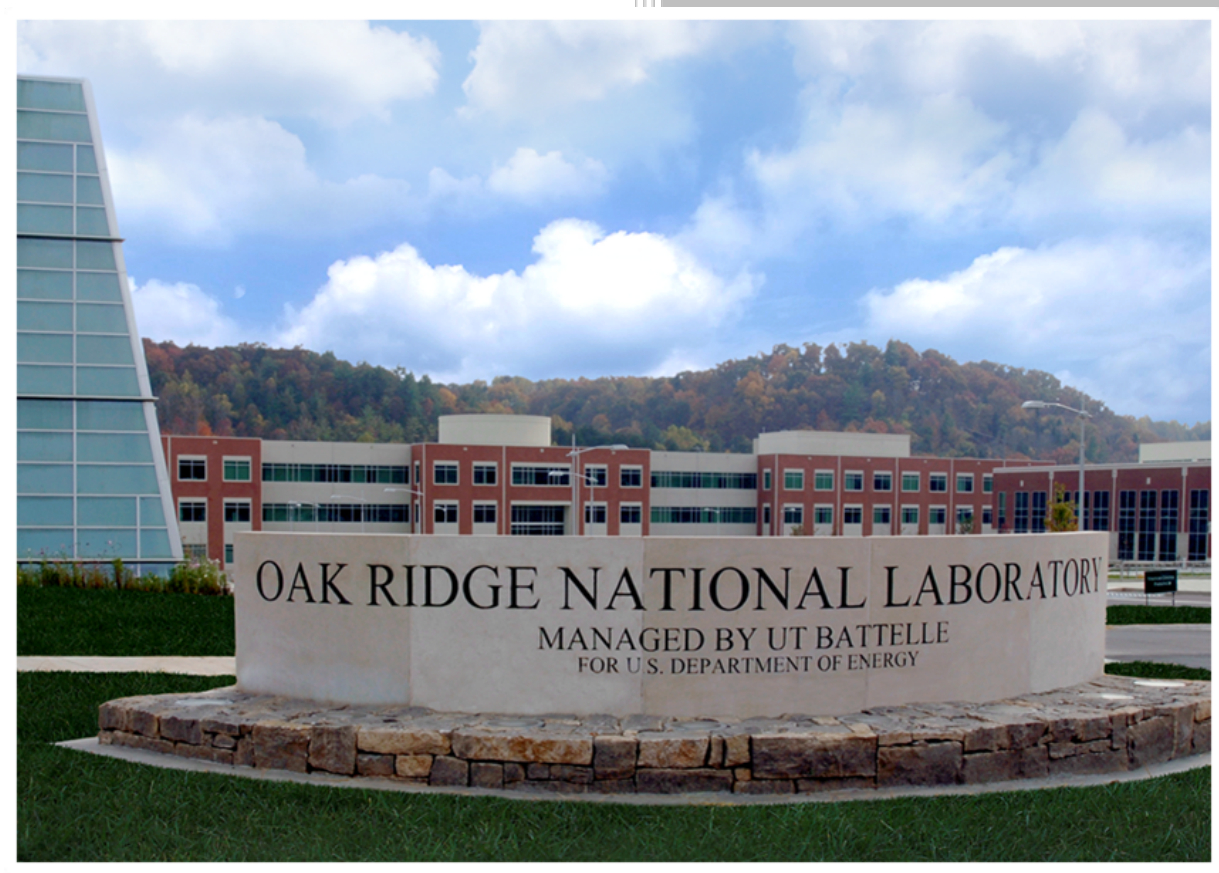

\section{Approved for public release.}

T. R. Watkins

E. A. Payzant

S. Babu

Distribution is unlimited. 


\section{DOCUMENT AVAILABILITY}

Reports produced after January 1, 1996, are generally available free via US Department of Energy (DOE) SciTech Connect.

Website http://www.osti.gov/scitech/

Reports produced before January 1, 1996, may be purchased by members of the public from the following source:

National Technical Information Service
5285 Port Royal Road
Springfield, VA 22161
Telephone 703-605-6000 (1-800-553-6847)
TDD 703-487-4639
Fax 703-605-6900
E-mail info@ntis.gov
Website http://www.ntis.gov/help/ordermethods.aspx

Reports are available to DOE employees, DOE contractors, Energy Technology Data Exchange representatives, and International Nuclear Information System representatives from the following source:

Office of Scientific and Technical Information

PO Box 62

Oak Ridge, TN 37831

Telephone 865-576-8401

Fax 865-576-5728

E-mail reports@osti.gov

Website http://www.osti.gov/contact.html

This report was prepared as an account of work sponsored by an agency of the United States Government. Neither the United States Government nor any agency thereof, nor any of their employees, makes any warranty, express or implied, or assumes any legal liability or responsibility for the accuracy, completeness, or usefulness of any information, apparatus, product, or process disclosed, or represents that its use would not infringe privately owned rights. Reference herein to any specific commercial product, process, or service by trade name, trademark, manufacturer, or otherwise, does not necessarily constitute or imply its endorsement, recommendation, or favoring by the United States Government or any agency thereof. The views and opinions of authors expressed herein do not necessarily state or reflect those of the United States Government or any agency thereof. 
Materials Science \& Technology Division Chemical \& Engineering Materials Division Energy \& Transportation Science Division Advanced Manufacturing Office

\title{
Neutron Characterization of Additively Manufactured Components: Workshop Report
}

\author{
T. R. Watkins (ORNL) \\ E. A. Payzant (ORNL) \\ S. Babu (UTK, ORNL)
}

SEPTEMBER 2015

Prepared by

OAK RIDGE NATIONAL LABORATORY

Oak Ridge, TN 37831-6283

managed by

UT-BATTELLE, LLC

for the

US DEPARTMENT OF ENERGY

under contract DE-AC05-00OR22725 



\section{CONTENTS}

CONTENTS

1. Summary 1

2. Workshop Motivation and Objectives 1

3. Synopsis of Panel Discussion 2

3.1 Modes of Access 2

3.2 New Neutron Capabilities Needed 3

3.3 New AM Materials Issues and Neutrons 3

4. Workshop Recommendations 4

4.1 Modes of Access 4

4.2 New Neutron Capabilities Needed 4

4.3 New AM Materials Issues and Neutrons 4

5. Acknowledgements 4

Appendices
A. - Agenda
B. - Participants
8 


\section{NEUTRON CHARACTERIZATION OF ADDITIVELY MANUFACTURED COMPONENTS WORKSHOP REPORT}

\section{SUMMARY}

Additive manufacturing (AM) is a collection of promising manufacturing methods that industry is beginning to explore and adopt. Macroscopically complicated and near net shape components are being built using AM, but how the material behaves in service is a big question for industry. Consequently, AM components/materials need further research into exactly what is made and how it will behave in service.

This one and a half day workshop included a series of invited presentations from academia, industry and national laboratories (see Appendix A for the workshop agenda and list of talks). The workshop was welcomed by Alan Tennant, Chief Scientist, Neutron Sciences Directorate, ORNL, and opened remotely by Rob Ivestor, Deputy Director, Advanced Manufacturing Office-DOE, who declared AM adoptees as titans who will be able to create customized 3-D structures with 1 million to 1 billion micro welds with locally tailored microstructures. Further he stated that characterization with neutrons is key to be able to bring critical insight/information into the AM process/property/behavior relationship. Subsequently, the presentations spanned a slice of the current state of the art AM techniques and many of the most relevant characterization techniques using neutrons. After the talks, a panel discussion was held; workshop participants (see Appendix B for a list of attendees) providing questions and the panel answers. The main purpose of the panel discussion was to build consensus regarding the critical research needs in AM that can be addressed with neutrons. These needs were placed into three categories: modes of access for neutrons, new capabilities needed, new AM material issues and neutrons. Recommendations from the workshop were determined based on the panel discussion.

\section{WORKSHOP MOTIVATION AND OBJECTIVES}

Oak Ridge National Laboratory (ORNL) provides the only co-located reactor (High Flux Isotope Reactor or HFIR) and accelerator-based (Spallation Neutron Source or SNS) neutron sources in the world. Access to neutron-based research techniques potentially provides an important competitive advantage to USbased manufacturing, however the availability of neutron-based materials characterization is not well known to researchers in industry and to date there is only limited industrial utilization of instruments at neutron sources.

The recent establishment of the Manufacturing Demonstration Facility (MDF) at ORNL, with its strong focus on "additive manufacturing" ("AM", also known as "3D Printing"), provides industry with affordable and convenient access to facilities, tools and expertise to facilitate rapid deployment of advanced manufacturing technologies to enhance the competitiveness of U.S. manufacturing.

Recent projects initiated by university and MDF researchers have applied neutron scattering methods to obtain unique microstructural data on additively manufactured parts. The motivation of this workshop was to gather a community of AM manufacturers and researchers together to discuss neutron characterizations available now, future neutron characterizations needed, industrial access mechanisms to neutrons and to visit/tour ORNL's Manufacturing Demonstration Facility, HFIR and SNS.

The objectives of the workshop were inform industry of the neutron characterization options available and obtain industrial perspectives and needs with regards to the following:

1.) Modes of access to neutron facilities for industry AM research 
2.) New neutron capabilities needed to meet industry AM needs

3.) New AM materials issues and new neutron capabilities

The workshop concluded with a panel discussion that reviewed and analyzed all aspects of the workshop topics, with questions from the audience and answers from the panel. The panel members were: Roger England (Cummins Inc.), James Neumann (Honeywell Aerospace), Andrew Payzant (ORNL), and Ken Tobin (ORNL).

\section{MAIN DISCUSSION POINTS}

\subsection{MODES OF ACCESS}

The panel discussion opened with a discussion about the current modes of access to obtain neutron time, for which there was considerable interest. It was stated that at present, neutron time at each ORNL beamline at HFIR or SNS is divided between $75 \%$ general user time and $25 \%$ discretionary time. The allocation of the general user time is accomplished by external peer review of proposals solicited twice a year. If accepted through the general user proposal process, access to the neutrons and support staff is at no cost to the user so long as the work will be published in the open literature. There are single-user-visit general user proposals and multi-visit/longer-term general user proposals, called programmatic proposals. Here, priority could be given to national programs. Similarly, the discretionary time is divided amongst proof-of-principal, programmatic, instrument scientist and rapid access proposals. The latter is intended to be well suited for industry in particular. Another access option is a Work-for-Others (WFO) project, which is different in that the industry pays for the neutron time and staff time (full-cost recovery) in exchange for the work being treated as proprietary (not to be published). It was noted by several participants and audience members that manuscripts often don't need to include what is considered proprietary (e.g., process parameters) or export-controlled (e.g., application-specific) in order to be to publishable. It was pointed out that industry often has its own, sometimes lengthy, review process to make sure out-going proposals and publications are "safe" to release.

The neutron user program seeks balance of projects amongst academia, industry and government labs. The current approval rate for the general user proposal process is $25-30 \%$. Proposal acceptance is primarily based on science merit; however, industrial problems are also welcome so long as they are important/impactful. Correspondingly, all forms of publications: journals, proceedings, graduate theses, books and technical reports, are regarded well if impactful. Winning proposals are generally clear about "What is the question that needs to be answered with neutrons?"

A comment was made that a proposal process map/flowchart would be helpful along with a special equipment list (e.g., torsional load frame, magnetics, furnaces, etc.). Further, a comment was made regarding the need for an on-site industrial person/liaison to guide industrial users through this process. An email survey was proposed addressing what industry would prefer as a mechanism/process for neutron access. A question from the audience inquired after the availability/need for a concierge service or surrogate user to assist or even substitute for industrial personnel with the experimental work, data analysis and report writing. This has benefits especially in times of target instability or limited special equipment availability. Information about the mail-in-program for POWGEN was well received, and discussed as a possible model for other beamlines. Where a "standard sample" (e.g., a few grams of powder in a vanadium can, as at POWGEN) can be defined, a mail-in program offers significant advantages to both the user (in terms of ease/cost of access) and the facility (in terms of data throughput).

The advantages of research consortia were discussed, which one panelist regarded as "stellar". These can be tricky to implement, as each company's work needs are very specific. Nonetheless, if a future AM 
consortium had access to a suite of beamlines (though a programmatic proposal or other mode of access), coupled with a broad and justifiable focus, it could work. A recent research consortium effort between Honeywell, General Electric, and Pratt \& Whitney on additive manufacturing in aerospace materials was cited as an example - some research on this project was carried out at the VULCAN instrument at the SNS by Dr. Iuliana Cernatescu (Pratt \& Whitney). For any such research consortium, issues regarding data management and data and specimen retention need to be sorted out, but this has been done successfully in other cases. One benefit of consortium-based research is that once industry gets its broad answers, both fundamental follow-on work and targeted projects can be identified and either proposed as proprietary industry projects or as non-proprietary industry-funded academic (university) work.

\subsection{NEW NEUTRON CAPABILITIES NEEDED}

The presentations given by Craig Brice (National Aeronautics and Space Administration (NASA)), Don Brown (Los Alamos National Laboratory (LANL)) and Tony Rollett (Carnegie Mellon University $(\mathrm{CMU})$ ) all highlighted the need for neutron texture measurements within the AM research envelope. It became clear that a neutron texture beamline, comparable to HIPPO (Lujan Center at Los Alamos Neutron Center (LANSCE)) is needed nationally given the uncertain future of HIPPO. Such a beamline would help to map and describe the evolving texture particularly along the various orientations of AM builds/components in order to intelligently modify processing parameters to control the microstructure. Texture information is required by models/ Integrated Computational Materials Engineering (ICME) in order to find the boundary conditions, predict component behavior, properties, etc.

Another theme from Craig Brice's (NASA) talk was the concept of "experiments on a pallet." The idea being that a researcher brings their experiment to the beamline mounted on some sort of a standard fixture, facilitating the experiment and saving precious neutron time for sample alignment. Discussions of open flame/fuel injectors, friction stir rigs and indentation experimental pallets were actively discussed.

\subsection{NEW AM MATERIAL ISSUES AND NEUTRONS}

This was topic did not get a lot of panel time, but was highlighted in several of the presentations and discussions. One area highlighted by Tony Rollett (CMU) had to do with the AM feedstock powders and reuse of same to make subsequent AM components. It became clear that these expensive powders cannot be recycled infinitely without degrading the final product with inclusions and voids, but the exact nature of powder degradation is not yet completely understood (i.e, when to stop recycling). Similarly the question arose "Are there acceptable particle size and shape distributions that enable repeatable product quality." Jim Neumann (Honeywell Aerospace) commented on the need for standard and specifications for AM as well as "life-ing" or proof-testing of AM parts prior to service. In these cases, neutron tomography will be valuable to find and characterize voids and defects in related studies. Additionally, Bragg-edge imaging can potentially provide a more rapid way to simultaneously image a part and determine its average residual (or applied) stress state and texture.

\section{RECOMMENDATIONS}

\subsection{MODES OF ACCESS}

1. An industrial proposal process map/flowchart coupled with a special equipment list is needed. A web-based survey was proposed for addressing what industry would prefer as an access mechanism/process for neutrons. This could be executed in summer or fall 2015.

2. An on-site industrial person/liaison to guide industrial users through this process was desired. This person would handle industrial enquiries, tours, assist with proposal writing and 
submission, perform outreach at meetings, assist with data collection and analyses (see item 3 below). A strong customer-service motivation is needed.

3. Most industrial researchers are not experts in neutron scattering characterization. From the workshop discussion, there was much support for the idea of establishing a "concierge" service, including a staff member at ORNL (or possibly through the Joint Institute for Neutron Sciences (JINS)) with a dedicated role to assist (or even substitute for) industrial personnel with the experimental work, data analysis, and/or report writing. This individual will need a strong industrial materials background in addition to detailed knowledge of neutron scattering instruments at HFIR/SNS.

\subsection{NEW CAPABILITIES NEEDED}

4. Crystallographic orientation (texture) is critical to properties of all engineered materials, and particularly for AM parts, as the process tends to create significant anisotropy in properties and structure. The one dedicated instrument for this purpose in the US was HIPPO at the LANSCE neutron facility at Los Alamos. However, the DOE Basic Energy Science (BES) user program that facilitated access to this beamline has recently concluded. The need for ORNL to have a comparable neutron texture beamline was cited by the workshop participants as a high priority. Such a beamline at either HFIR or SNS would be quite useful not only for $\mathrm{AM}$, but also conventional manufacturing processes. Industrial needs include not only static characterization of texture in engineered parts, but also the capability to study in-situ evolution of phases and texture in parts under load, temperature, field, or combinations thereof. This capability could be realized through a combination of detector, sample environment, and software upgrades to NOMAD and/or VULCAN, and advanced further by construction of VENUS (i.e., Time of Flight (TOF) neutron imaging). However, the software needed for texture analysis at VENUS does not yet exist, and would need to be developed in parallel with the beamline itself.

5. The concept of "experiments on a pallet" (an allusion to "experiments on a chip" only at a much larger physical scale) should be considered as a way to standardize some in-situ testing using ORNL-defined fixtures. This would reduce set up time by enabling new large-scale "standard" sample setups for complex characterization, which presently are inefficiently handled on a "case by case" basis. This has not been done to date at neutron sources but has been effective at optimizing experiment time elsewhere (e.g., microgravity experiments).

\subsection{NEW AM MATERIALS ISSUES AND NEUTRONS}

6. Several participants noted the importance of the starting powders in AM. It is clear that the powder quality directly impacts the quality of the as-built part, and the quality degrades with each reuse of unconsolidated powder from one run to the next. Reuse of powder is a key factor in the cost of production, so neutron scattering techniques (such as imaging, diffraction, and potentially Small Angle Neutron Scattering (SANS)) could provide unique insights into the nature of the starting and recycled powder quality to help identify the key powder degradation parameters.

\section{ACKNOWLEDGMENTS}

This workshop was sponsored by: (1) the Scientific User Facilities Division, Office of Basic Energy Sciences, U.S. Department of Energy, (2) the Laboratory Directed Research and Development Program of Oak Ridge National Laboratory, managed by UT-Battelle, LLC, for the U. S. Department of Energy, and (3) the U.S. Department of Energy, Office of Energy Efficiency and Renewable Energy, Advanced 
Manufacturing Office, under contract DE-AC05-00OR22725 with UT-Battelle, LLC. Special thanks to Ms.'s Titonia Sawyer, Rita Ayers and Brittany Piercy for their administrative support and organizational help in making this workshop a reality. 


\section{APPENDIX A. WORKSHOP AGENDA}

\section{黨OAK RIDGE National Laboratory \\ AGENDA}

MANAGED BY UT-BATTELLE FOR THE US DEPARTMENT OF ENERGY

Neutron Characterization of Additively Manufactured Components Workshop

February 25-26, 2015

Building 8600 , Iran Thomas Auditorium

\begin{tabular}{|c|c|c|}
\hline Time & Event & Leader \\
\hline \multicolumn{3}{|c|}{ Wednesday, February 26, 2015} \\
\hline $7: 30-8: 25$ a.m. & Registration / Coffee & \\
\hline $8: 25-8: 35$ a.m. & Welcome, Opening Remarks & Alan Tennant, ORNL \\
\hline $8: 35-8: 45$ a.m. & Workshop Objectives & $\begin{array}{l}\text { Bill Peter, ORNL } \\
\text { Rob Ivestor, AMO DOE }\end{array}$ \\
\hline $8: 45-9: 30$ a.m. & Keynote Address: Industrial Perspectives & $\begin{array}{l}\text { James Neumann } \\
\text { Honeywell Aerospace }\end{array}$ \\
\hline 9:30-10:15 a.m. & AM Manufacturing Techniques & Craig Brice, NASA Langley \\
\hline 10:15-10:45 a.m. & BREAK & \\
\hline 10:45-11:30 p.m. & AM Microstructure and Texture & Tony Rollett, CMU \\
\hline 11:30 a.m. $-12: 15$ p.m. & Neutron Imaging & Ken Tobin, ORNL \\
\hline 12:15-1:15 p.m. & $\begin{array}{l}\text { Tour sign-ups and pick-up lunch (lobby) } \\
\text { Methods to work with ORNL (working lunch) } \\
\text { Conference Rooms C464 (live) and C250 (simulcast) }\end{array}$ & $\begin{array}{l}\text { Nestor Franco, ORNL, } \\
\text { Technology Transfer }\end{array}$ \\
\hline $1: 15-2: 00$ p.m. & Residual Stress Mapping for AM & Don Brown, LANL \\
\hline 2:00-2:45 p.m. & Second Target Station and New Capabilities & Alan Tennant, ORNL \\
\hline 2:45-3:15 p.m. & BREAK & \\
\hline $3: 15-4: 45$ p.m. & $\begin{array}{l}\text { Panel Discussion: } \\
\text { Modes of access for neutrons; New } \\
\text { capabilities needed; New AM material issues } \\
\text { and neutrons }\end{array}$ & $\begin{array}{l}\text { Andrew Payzant, Moderating } \\
\text { James Neumann, Honeywell } \\
\text { Aerospace } \\
\text { Roger England, Cummins } \\
\text { K. Tobin, ORNL }\end{array}$ \\
\hline 4:45-5:30 p.m. & Travel to MDF & \\
\hline 5:30-7:30 p.m. & $\begin{array}{l}\text { Interactive Tour of MDF followed by a reception with } \\
\text { heavy hors d'ouvres }\end{array}$ & Bill Peter \\
\hline 7:30-8:00 p.m. & Adjourn & \\
\hline
\end{tabular}




\section{: OAK RIDGE \\ National Laboratory \\ AgENDA}

MANAGED BY UT-BATTELLE FOR THE US DEPARTMENT OF ENERGY

\begin{tabular}{|l|l|l|}
\hline \multicolumn{1}{|c|}{ Time } & \multicolumn{2}{c|}{ Lvent } \\
\hline Thursday, February 26, 2015 & \\
\hline 7:30-8:15 a.m. & Registration / Coffee \\
\hline 8:15-8:45 a.m. & Experimental Validation of Models with Neutrons & Suresh Babu, UTK/ORNL \\
\hline 8:45 a.m. & Tour SNS: stops at VULCAN and Powgen & $\begin{array}{l}\text { SNS Tour Guides: } \\
\text { A. Payzant, E. Cakmak, L.Kolbus, } \\
\text { Ke An }\end{array}$ \\
\hline 10:15 a.m. & Travel to HFIR & $\begin{array}{l}\text { HFIR Tour Guides: } \\
\text { A. Payzant, E. Cakmak, L.Kolbus, } \\
\text { K. Littrell, T. Watkins \& J. Bunn }\end{array}$ \\
\hline 10:30 a.m. & Tour HFIR: stops at RS and Imaging & \\
\hline 12:00 p.m. & Return to SNS & \\
\hline 12:15 p.m. & Adjourn & \\
\hline
\end{tabular}




\section{APPENDIX B. WORKSHOP ATTENDEES}

\begin{tabular}{|c|c|c|c|}
\hline Last Name & First Name & Email & Affiliation \\
\hline Babu & Sudarsanam & sbabu@utk.edu & University of Tennessee/ORNL \\
\hline Brice & Craig & craig.a.brice@nasa.gov & NASA Langley Research Center \\
\hline Cakmak & Ercan & cakmake@ornl.gov & ORNL \\
\hline Thibadeau & Barbara & bthibadeau@sns.gov & ORNL \\
\hline Bilheux & Hassina & bilheuxhn@ornl.gov & ORNL/SNS \\
\hline Anderson & David & andersondc@ornl.gov & ORN: / SNS \\
\hline Rollett & Anthony & rollett@cmu.edu & Carnegie Mellon University \\
\hline Mohammed & $\begin{array}{l}\text { Gous } \\
\text { Mohiuddin }\end{array}$ & gous.m.mohammed@cummins.com & Cummins Inc. \\
\hline Bunn & Jeff & bunnjr@ornl.gov & Oak Ridge National Laboratory \\
\hline An & $\mathrm{Ke}$ & kean@ornl.gov & ORNL/CEMD \\
\hline Ross & William & rossw@ge.com & GE Global Research \\
\hline Duty & Chad & dutyc@ornl.gov & ORNL \\
\hline Dehoff & Ryan & dehoffrr@ornl.gov & Oak Ridge National Lab \\
\hline Abbott & David & dave.abbott@ge.com & GE Aviation \\
\hline Neumann & Jim & james.neumann@honeywell.com & Honeywell \\
\hline Brophy & Erin & brophye@ornl.gov & ORNL \\
\hline Franc & Alan & Afranc@techmeres.com & Techmer ES \\
\hline Santodonato & Louis & santodonatol@ornl.gov & Oak Ridge National Laboratory \\
\hline Bilheux & Jean & bilheuxjm@ornl.gov & $\begin{array}{l}\text { ORNL - SNS - Neutron Science } \\
\text { Directorate }\end{array}$ \\
\hline Watkins & Thomas & watkinstr@ornl.gov & ORNL \\
\hline Kolbus & Lindsay & kolbuslm@ornl.gov & Oak Ridge National Lab \\
\hline Franco & Nestor & francone@ornl.gov & ORNL \\
\hline Augustine & Brent & AugustineBrentA@JohnDeere.com & Deere \& Co. \\
\hline Holl & Stephen & steve.holl@cummins.com & Cummins \\
\hline Crofts & John D. & cc601@cummins.com & Cummins Emission Solutions \\
\hline Ross & Steven & steven.ross@cummins.com & Cummins Inc. \\
\hline Tobin & Kenneth & tobinkwjr@ornl.gov & Oak Ridge National Laboratory \\
\hline Brown & Don & dbrown@lanl.gov & Los Alamos National Lab \\
\hline England & Roger & dd474@cummins.com & Cummins, Inc. \\
\hline Peter & William & peterwh@ornl.gov & ORNL \\
\hline Pal & Deepankar & d0pa1001@louisville.edu & University of Louisville \\
\hline Wieland & Todd & todd.m.wieland@cummins.com & Cummins Inc. \\
\hline Simon & Conrad & conrad.j.simon@cummins.com & Cummins, Inc. \\
\hline Bhatnagar & Sanjay & sanjay.bhatnagar@cummins.com & Cummins, Inc. \\
\hline De Hart & Taren & taren.dehart@cummins.com & Cummins Incorporated \\
\hline
\end{tabular}




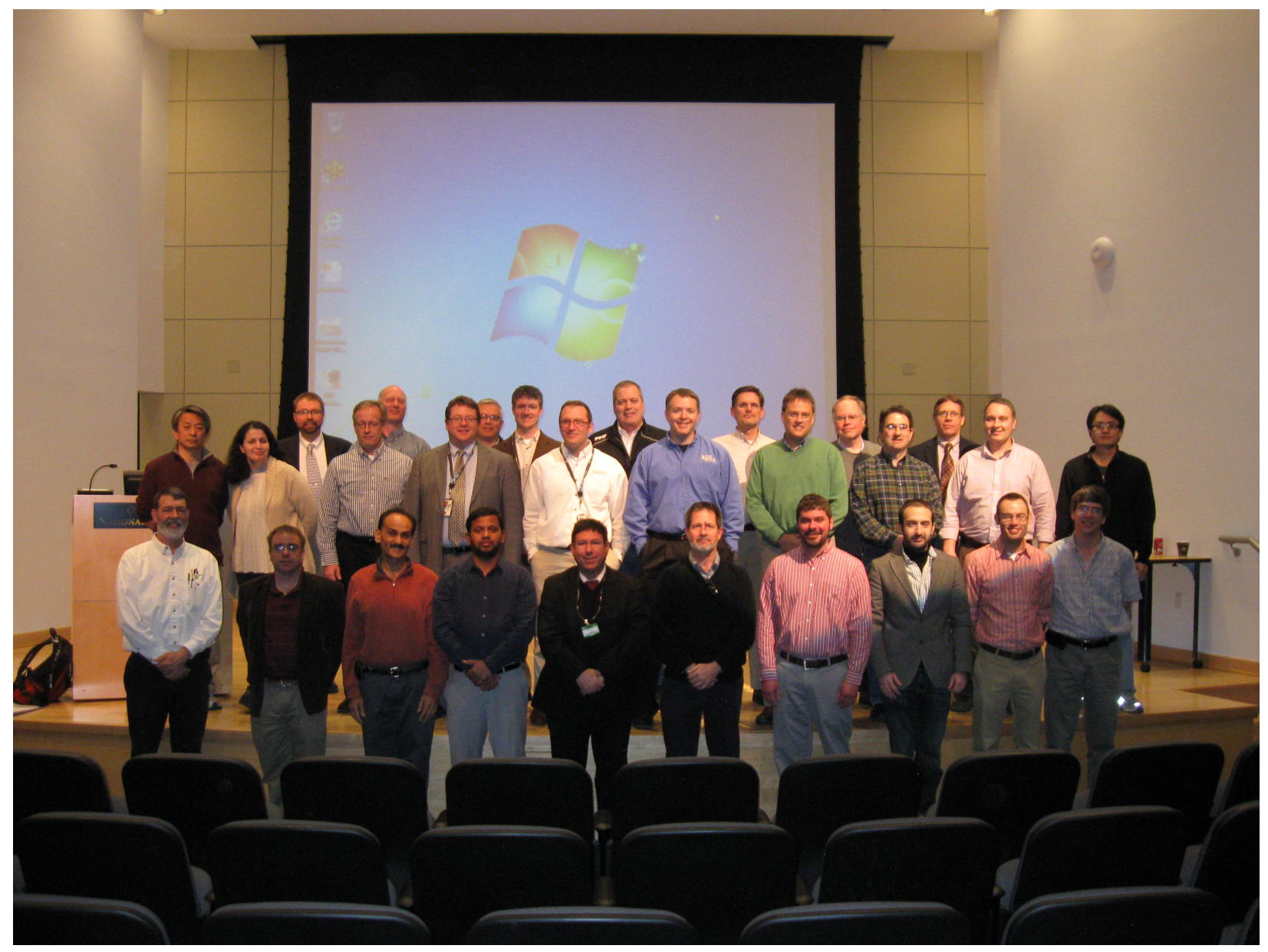

Most of the attendees of the Neutron Characterization of Additively Manufactured Components Workshop. Front row (left to right): John Crofts, Don Brown, Sanjay Bhatnagar, Gous Mohammed, Jim Neumann, Ken Tobin, Brent Augustine, Ercan Cakmak, Unknown, Andrew Payzant. Middle row: Yan Gau, Hassina Bilheux, David Abbott, Bill Peter, Ryan Dehoff, Chad Duty, Phil Bingham, Lou Santodonato, Taren De Hart, Ke An. Last Row: Thomas Watkins, Steve Holl, Roger England, Craig Brice, Steve Ross, Unknown, Bill Ross, Todd Wieland. 